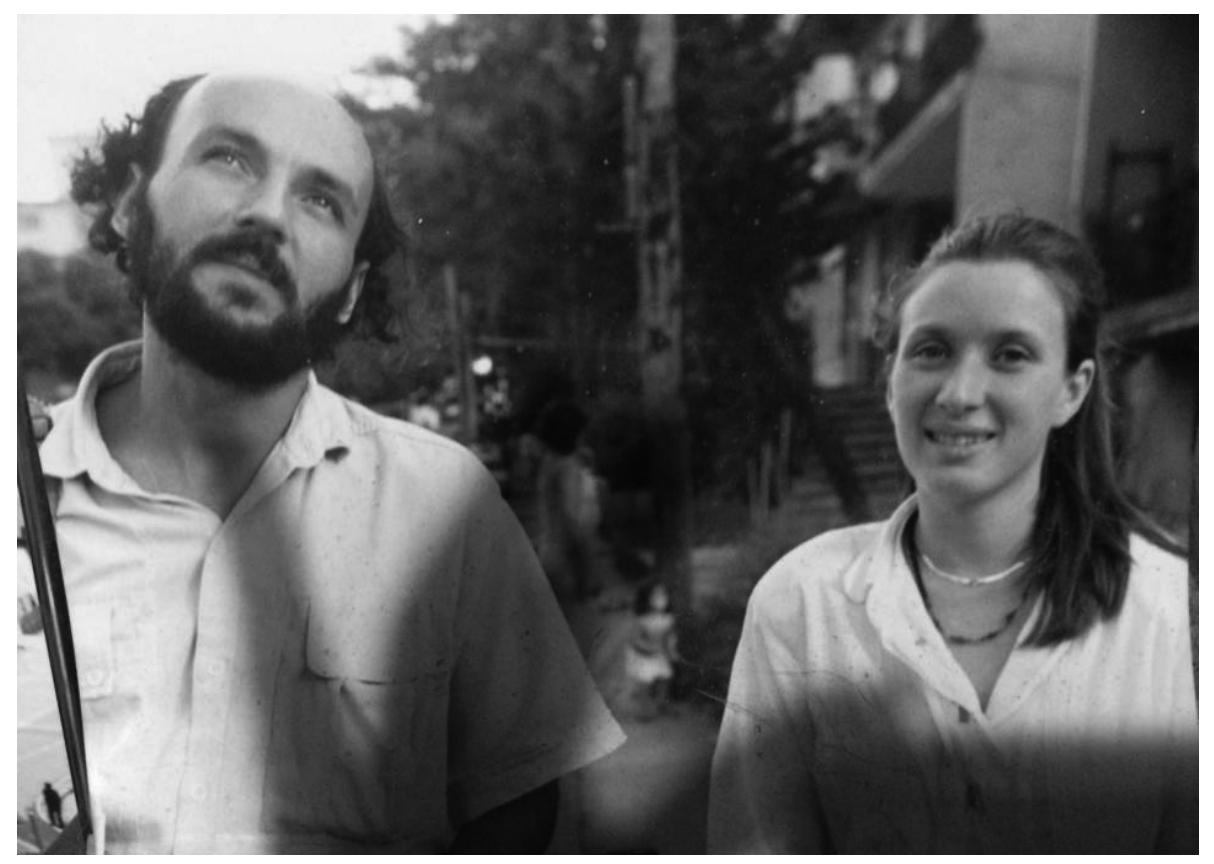

Alfredo y Ana. Foto del archivo personal de Allan Barboza-Leitón. 


\begin{tabular}{llllllllllllllllllll}
$\mathbf{R}$ & $\mathbf{E}$ & $\mathbf{P}$ & $\mathbf{E}$ & $\mathbf{R}$ & $\mathbf{T}$ & $\mathbf{O}$ & $\mathbf{R}$ & $\mathbf{I}$ & $\mathbf{O}$ \\
\hline Segunda nueva época $\mathrm{N}^{\circ}$ 29, Enero-Diciembre, 2019 & $\mathbf{A}$ & $\mathbf{M}$ & $\mathbf{E}$ & $\mathbf{R}$ & $\mathbf{I}$ & $\mathbf{C}$ & $\mathbf{A}$ & $\mathbf{N}$ & $\mathbf{O}$ \\
\hline
\end{tabular}

\section{Testimonio: Joaquín 30 y el Cheje}

Allan Barboza- Leitón

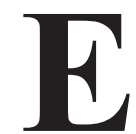
staba yo recién llegado al Frente. Como dicen por aquí: pollito, blandito, tiernito. Como quien dice: un filetito listo para echarlo a las brasas de la guerra. Y en esos tiempos, a mí me gustaba mucho platicar con la gente, y por supuesto la gente más interesante, $\mathrm{o}$ al menos para mí.

Y resulta que había dos compañeros famosos, mejor dicho tres. Porque el hecho de que alguien sea cuadrúpedo no le quita la condición humana. ¡No jodan, hombre! Hoy se tienen a un cuadrúpedo ahí en la Casa Blanca, que ese rebuzna y berrea peor que el burro más burro de las montañas. Hay burros a los que les debemos la Patria que tenemos. Hay burros que son próceres, que son padres de esta Patria. Ese era el tercer compañero. Luego estaban Joaquín 30 y el Cheje.

La historia de Joaquín es especial. Resulta que al mero comienzo de la guerra atacamos un penal que se llama Mariona, y reventamos las puertas, un par de muros, y salieron al patio. $Y$ en el patio nosotros les dijimos, pues, el objetivo de la lucha. $Y$ les planteamos: los que quieran incorporarse y devolverle a la sociedad el daño que le han causado, que se unan con nosotros. Y pues fíjese que entre los que se nos unieron iban dos: un tal Joaquín, que había sido ni más ni menos que Guardia
Nacional, y un payaso. El Cheje, payasito de circo, pícaro, redomado, flaquito y chiquito. Joaquín era moreno, sólido, mediana estatura, expresión de "¿a ver quién es la ley?". Como quien dice: cara de pocos amigos. Y se fueron con nosotros a la zona baja del Volcán Guazapa.

Resulta que nosotros le hacemos un ataque a un puesto que tenía el ejército en el Volcán, como tantas veces se había hecho, y viene el ejército y nos responde con una invasión. ¡Ay mamita! Hacerle güevo, en aquella planería, al animalero que verdeaba todo el plano... Es que venían como manada de chuchos tras un zorrito: sedientos. Los generales les habían dado paja, y los pobres soldaditos iban creyendo que solo iban a llegar a almorzar... Miren, entre más desesperada es la cosa más recursos echa la vida para la guerra.

Nosotros iniciamos la retirada escalonada. Y llegamos a un punto en que el escalonamiento tenía una línea al frente del enemigo, una línea de compañeros guerrilleros que los retrasaba, mientras el grueso de población civil avanzaba buscando la salida. En aquellos días, estaba comandando el Frente de Guazapa la compañera Lorena, su nombre de guerra era Rebeca. Lorenona le decían los campesinos, iporque era altísima esa mujer! Morena, nariz respingada, una mente ágil y una sonrisa un toque irónica. 
Pero firme. Lorena dio la orden de sacar EL ARMA. Oigan lo que les estoy diciendo: EL ARMA que poseía el Frente. Su última esperanza era que esa arma, con su terrible potencia de fuego, contuviera al enemigo, termináramos de evacuar la cuestión, y los del arma y sus acompañantes se quedaran diluidos en el terreno.

Bueno, sacan el arma, la montan en su lugar... ¡ es que no la podía sostener un solo hombre! Le instalan las cananas, brillantes, limpiecitas, cada una de las balas llevaba el nombre de un desgraciado alevoso. Y bueno, entra en acción el compa responsable del arma. Apunta y deja ir aquello. Miren, aquello sí sonaba bonito... ¡BUURRRNNN! Tira el primer balazo, y para el segundo: ¡kicrt, kicrt, kicrt! ¡hijueputa! ¡se taqueó! A desarmar la babosada, limpiar el cañón con el casquillo usado, volverla a armar y ¡listo! ¡vamos al segundo! ¡BUURRRNNN! ¡kicrt, kicrt, kicrt! ¡Puta! ¡tres veces! ¡Y los animales ya cerca! Y Rebeca allí, no es que había salido de cabeza. Entonces viene ella y dice:

\section{- ¿Quién sabe usar esta mierda?}

Hombre porque es cierto, sí era EL ARMA y salía que con cada tiro se encasquillaba, ¡no joda! Y entonces uno de los que venían allí se ofreció.

- ¿Y vos cómo sabés?

- Yo fui guardia, y esas usaban...

- ¿y sabés cual es el mal que tiene esa arma?

- El arma está bien...
- ¿Entonces qué pasa?

- Que no la saben usar...

- Bueno, tu misión es contenerlos, mirá: ya vienen cerca. Y tu misión es - le dice Rebeca a otro compa - contenerlo a él...

- Ah - dijo Joaquín - yo necesito alguien que me agite la canana...

Ni sabíamos que era eso. Y entonces Rebeca volteó a ver al otro lado y de los mismos de Mariona llamó al flaquito, y ya Joaquín le dijo al flaquito lo que tenía que hacer. Era simplemente darle un bamboleo a la canana para facilitar el engranaje de cada tiro al ritmo que llevara Joaquín las ráfagas. Y rápido le agarró el Cheje.

Luego el Cheje se hizo famoso, inventó un baile que se bailaba en todos los Frentes de guerra: el "meneadito". Venía el Cheje, agarraba la canana, la ponía en medio de las dos manos y empezaba "ta ta ta ka, ta ta ka, ta ta ta ka, ta ta ka, ta ta ta ka, ta ta ka". Y al rato ya el Cheje no solo movía las manos, ya con la cabecita le llevaba el ritmo, con la cadera y por último era un rumbón del carajo... ¡con todo el cuerpo! Pasándolas. Y el Joaquín feliz, ¡le rempujaba con ganas! Y así fue como se les conoció como Joaquín 30 y el Cheje.

Hasta aquí todo es bonito, hombre. La guerra tiene cosas bonitas, como el meneadito del Cheje, pero tiene tanto dolor... tiene tanto dolor humano. Es la peor salvajada a la que pueden empujar a los pueblos. 
Después, a los pocos meses, le quitamos al enemigo la primera ametralladora punto 50. Arma de tierra con posibilidades de usarse contra aviones. Esa sí era EL ARMA, y la primera que se requisó se le dio a Joaquín 30 con su dotación completa: un burro de alta alzada, poderoso, valiente. $\mathrm{Y}$ entonces ellos tres convivían. A la hora del desayuno, el burro se venía del potrero a pararse en medio de Joaquín y el Cheje. Ahí estaban esperándolo con su tortillita con frijoles. Igual la cena, el almuerzo. Bueno, con decirles que lo llevaban a tomar café... Y yo me temo que alguna vez, no creo que Joaquín, el Cheje quizá, se ha de haber agarrado una borrachera nocturna con el burro, y ya me los imagino a los dos, cayéndose de la gran sirindanga, abrazado el uno del otro, gritándole a la luna las más añejas penas de amor. ¡Por algo el burro es burro! Por enamorado, y por burro.

Ellos estaban adscritos al batallón de armas de apoyo, lo más pesado, bajo el mando de un gran compañero. Y estaba la escuadra de ametralladoras. Por supuesto, el jefe de escuadra: Joaquín 30. Entonces cuando yo pasaba por ese campamento me acercaba y platicábamos mucho, con Joaquín y con el Cheje. Miren, allá como al año y medio de ser amigos, una noche ya tarde, yo me atreví a expresarle mi curiosidad a Joaquín, y con profundo respeto le dije: -Joaquín, ¿por qué te metieron preso?

Miren, el rostro de Joaquín cambió. Un velo de tristeza y de dolor emergió del corazón de él. Me sentí culpable de haber hecho eso. Entonces me dijo:
- En la guerra del Salvador y Honduras yo iba con el Chele Medrano...

Que era un general drogadicto, un general que se inyectaba morfina. Y entonces resulta que el Chele Medrano se tomó una zona de Honduras, y con lo bestia que era prácticamente que él azuzaba a los guardias, a robar, a violar, a matar, a una población que por siglos no sabía si era hondureña o salvadoreña. Joaquín estuvo allí.

Fíjese que cuando regresaron les hicieron el gran desfile de la victoria, a lo Rubén Darío, ¿recuerdan?

"Ya viene el cortejo, ya viene el cortejo ya se escuchan los claros clarines..."

Así se lo hicieron. Y poco faltó para que Tapón Sánchez, que se llamaba el presidente de la República, se mandara a poner una bota para salir de Nerón. Pero Joaquín me decía:

- Yo venía en uno de los camiones de la Guardia, yo no venía alegre, yo venía triste...

$\mathrm{Y}$ al bajar la gente los agarraba, en esa locura del patriotismo barato, y se los llevaba a los bares y los restaurantes, a descargar sus malas consciencias. Y los soldados y los guardias allí se emborrachaban. Y después de eso si te vi ni te conozco, pendejo. Y lo mismo hizo el ejército: les dio una patada en el trasero, los dejó en la ciudad.

Joaquín tenía esposa, estaba recién casado, y una niña, y se fue a su pueblito. Allá llegó y meses después Joaquín se 
emborrachó, y llegó en la noche a la casa. Él me contó que lo último que él se acordaba es que en esa noche se acostó en la cama y se durmió, hasta que se despertó al día siguiente. Y cabal, Joaquín despertó, pero no en la cama: despertó tirado en el piso de tierra, sobre un charco de sangre, y en la mano el maldito machete con que en su locura había asesinado a su esposa y a su niña. Y así como estaba Joaquín se levantó, se fue a presentar, fue con los jueces a reconocer los cadáveres, y le clavaron la sentencia perpetua.

El Cheje, en silencio, a la par de nosotros, sentado en cuclillas, con la espalda arrecostada a un pedazo de muro de la casa en que estábamos, con un fueguito que nos habíamos hecho, guacal en mano miraba el fuego y bebía. Parecía que el Cheje también se bebía la hiel inmensa que anidaba en el corazón de Joaquín. No sé, pero eso me pareció en aquel momento. Joaquín había hablado hipnotizado frente a las llamas de las brasas, y yo, con la cabeza agachada, no despegaba la vista de la sombra de mis pies. Ahí mismo nos fuimos a dormir.

Días después, talvez semanas, montamos un ataque y usamos varios cerros circundantes al lugar atacado para colocar las ametralladoras y neutralizar el apoyo aéreo que el enemigo lanzaba en esos casos. Fulminante el ataque: los fuimos rempujando... vos sos, vos sos, y si no sos te llamás... hasta que los teníamos reducidos a un paredón. Mientras tanto, por un flanco no previsto, se nos infiltró el enemigo. Y entonces nos dan la orden de retirar las ametralladoras.
Joaquín siguió la orden como jefe de escuadra, dio las indicaciones de la retirada y mandó a sacar las otras dos ametralladoras mientras que él cuidaba. Miren compas, el burro que estaba allá abajo esperando, sabía lo que tenía que hacer. Se acercó a él, a rastras, con mucho cuidado, se acercó para cargar la ametralladora. En ese estado, ya desmontándola, apareció un helicóptero, y socó el fuego sobre ellos. Joaquín les dio la orden, al Cheje y al burro, de que se retiraran, que él la bajaba, y aprovechó un momento en el que el helicóptero tuvo que hacer un giro, para con todas las fuerzas del alma agarrar la ametralladora y su trípode, sacarla de la trinchera y caer sobre la loma donde estaba. Joaquín logró caer, el helicóptero ya no lo vio, tuvo que dar un círculo más amplio para detectarlo, y Joaquín avanzó a media altura. Él que se levanta para dar el otro envión y le dan el primer balazo en el pecho. Y Joaquín cayó. Otra vez el helicóptero a dar la vuelta. Joaquín le grita al Cheje:

\section{- ¡No se mueva!}

Se levanta y le pega otro jalón a la ametralladora, y se desliza aprovechando la pendiente. Quedó boca abajo, le metieron el segundo balazo. Después aprovechó la tercera vuelta, le pegó un jalón y la echó para adelante. Y así, acostado, esperó el cuarto balazo. El helicóptero dio la vuelta, Joaquín ya no se levantó. Hincado, alzó por arriba de su cabeza la ametralladora y el trípode, y se la tiró a los pies al Cheje cuando ya caía muerto.

Y la ametralladora se salvó, y Joaquín se salvó, y el Cheje se salvó, y el burro se salvó, de la condena histórica. 


\section{Testimonio de: Alfredo Zamora Rivas - "Julito Ama"1}

1 El testimonio anterior, fue recogido por el fotógrafo documental, costarricense, Allan Barboza- Leitón al excombatiente salvadoreño Alfredo Zamora Rivas, "Julito Ama". Alfredo fue uno de los fundadores de las Fuerzas Populares de Liberación Farabundo Martí, en El Salvador. Fue miembro de una familia que tuvo mucha participación en los acontecimientos históricos de aquel país. Su hermano Ernesto, "el Topo", cumplió arriesgadas tareas como miembro de una de las guerrillas salvadoreñas, la Resistencia Nacional. Su hermana Ángela, nombre de guerra "Lucía”, luchó junto a él en las filas de las FPL-FM, mientras que su hermano Rubén militó en las filas de la democracia cristiana, llegando a ser parte importante del equipo negociador de los Acuerdos de Paz y primer candidato a la presidencia del FMLN, al finalizar la guerra. A finales de los años setenta y a lo largo de la década del ochenta del siglo pasado, Alfredo jugó, él mismo, un importante papel en el área de comunicación y en el aparato diplomático de la guerrilla, hasta la firma de los Acuerdos de Paz.

Sin embargo, quien tuvo una influencia decisiva en su decisión de integrarse al movimiento armado, fue su hermano mayor, el Dr. Mario Zamora Rivas. Mario era Secretario General del Partido Demócrata Cristiano y procurador general de pobres, cuando fue asesinado por un escuadrón de la muerte mientras celebraba un cumpleaños en su casa, con amigos y familiares. Este acontecimiento tuvo un impacto brutal en la conciencia de Alfredo. La orden de asesinar al Dr. Zamora vino del mayor Roberto D'abuisson. El vil asesinato de Mario Zamora y, un mes después, el asesinato en plena homilía de Monseñor Oscar Arnulfo Romero, marcaron el inicio de una larga y dolorosa guerra, en la que Alfredo aportó sangre, dolor, sueños y esperanzas.

Alfredo Zamora Rivas tuvo una mente brillante y un enorme talento como estratega y comunicador. Herido en combate, y luego enfermo a raíz de una agresiva hepatitis B que casi le cuesta la vida, fue sacado de los frentes de guerra para, posteriormente, integrarlo al aparato internacional del FMLN. En esa travesía llegó primero a Cuba, en donde fue entrevistado por Eduardo Galeano para El libro de los abrazos, y posteriormente fue enviado a Costa Rica, en donde finalmente decidió radicarse. Tras la firma de los Acuerdos de Paz fue dueño y anfitrión del Café Sala Calle 15, en plena ciudad de San José. Alfredo murió el 30 de septiembre de 2010 a las 8:05 de la noche. 
